\title{
Transradial approach for diagnostic cerebral angiograms in the elderly: a comparative observational study
}

\author{
Cannon Greco Hiranaka \\ Thomas Jefferson University, cannon.greco-hiranaka@students.jefferson.edu \\ Ahmad Sweid \\ Thomas Jefferson University, ahmad.sweid@jefferson.edu \\ Somnath Das \\ Thomas Jefferson University, somnath.das@jefferson.edu \\ Joshua $\mathrm{H}$. Weinberg \\ Thomas Jefferson University, joshua.weinberg@jefferson.edu \\ Follow this and additional works at: https://jdc.jefferson.edu/si_ctr_2023_phase1 \\ 'reem El Naamani

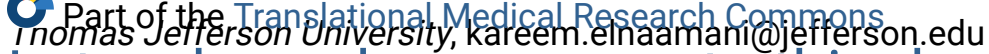 \\ Let us know how access to this document benefits you
}

\section{See next page for additional authors}

Recommended Citation

Greco Hiranaka, Cannon; Sweid, Ahmad; Das, Somnath; Weinberg, Joshua H.; El Naamani, Kareem; Kim, Julie; Curtis, Darcy; Joffe, Daniel; Vijaywargiya, Darshana; Sioka, Chrissa; Oneissi, Mazen; El Hajjar, Abdel Hadi; Gooch, Michael Reid; Herial, Nabeel; Tjoumakaris, Stavropoula I.; Rosenwasswer, Robert H.; and Jabbour, Pascal, "Transradial approach for diagnostic cerebral angiograms in the elderly: a comparative observational study" (2021). Phase 1. Paper 91. https://jdc.jefferson.edu/si_ctr_2023_phase1/91

This Article is brought to you for free and open access by the Jefferson Digital Commons. The Jefferson Digital Commons is a service of Thomas Jefferson University's Center for Teaching and Learning (CTL). The Commons is a showcase for Jefferson books and journals, peer-reviewed scholarly publications, unique historical collections from the University archives, and teaching tools. The Jefferson Digital Commons allows researchers and interested readers anywhere in the world to learn about and keep up to date with Jefferson scholarship. This article has been accepted for inclusion in Phase 1 by an authorized administrator of the Jefferson Digital Commons. For more information, please contact: JeffersonDigitalCommons@jefferson.edu. 


\section{Authors}

Cannon Greco Hiranaka, Ahmad Sweid, Somnath Das, Joshua H. Weinberg, Kareem El Naamani, Julie Kim, Darcy Curtis, Daniel Joffe, Darshana Vijaywargiya, Chrissa Sioka, Mazen Oneissi, Abdel Hadi El Hajjar, Michael Reid Gooch, Nabeel Herial, Stavropoula I. Tjoumakaris, Robert H. Rosenwasswer, and Pascal Jabbour 


\title{
Sidney Kimmel
}

Medical College.

at Thomas Jefferson University

\section{Transradial approach for diagnostic cerebral angiograms in the elderly: a comparative observational study}

\author{
Cannon Greco Hiranaka, * Ahmad Sweid
}


- The rapidly growing elderly population poses a unique challenge for the management of cerebrovascular disease.

- In this high-risk cohort, it has been demonstrated that the transradial approach (TRA) reduces risk of stroke, vascular complications, and death among patients undergoing coronary angiography.

- This project aimed to assess the technical success and safety of TRA for elderly patients (aged $\geq 75$ years) undergoing diagnostic cerebral angiograms. 


\section{Objectives} \& Hypothesis

- Research Question

- What is the technical success and safety of TRA for elderly patients (aged $\geq 75$ years) undergoing diagnostic cerebral angiograms?

- Hypothesis

- TRA is technical successful and safe for elderly patients (aged $\geq 75$ years) undergoing diagnostic cerebral angiograms 


\section{Approach \& Results}

- Study design

- Retrospective medical chart review and comparative analysis

- Population / study sample

- Patients aged 75 years or older who underwent TRA cerebral angiograms

- Patients aged 75 years and older who underwent TFA cerebral angiograms

- Patients aged less than 75 years who underwent TRA cerebral angiograms

- Data source and collection

- Thomas Jefferson Medical Charts 


\section{Approach \& Results}

- Rationale for Approach

- Compare differences between TRA and TFA approach in the elderly group.

- Compare differences between TRA approach between the elderly and their younger counterparts. 


\section{Approach \& Results}

- Analysis

- Analysis was performed using unpaired t-test, $\chi 2$, Fisher's exact tests, and ANOVA 


\section{Approach \& Results}

- Findings

- Comparative analysis in the elderly (TRA vs TFA) showed

- No significant differences for contrast dose per vessel, fluoroscopy time per vessel, procedure duration, conversion rate, and access site complications.

- Radiation exposure per vessel was significantly lower in the elderly TRA group. 


\section{Approach \& Results}

- Findings

- The second comparison (TRA in elderly vs TRA in the young) showed

- No significant differences for contrast dose per vessel, radiation exposure per vessel, procedure duration, access site complication, and conversation rate.

- A trend for prolonged fluoroscopy time per vessel was observed in the elderly TRA group. 


\section{Conclusions}

- Summary

- TRA is a technically feasible and safe option for diagnostic neurointerventional procedures in the elderly.

- Our small elderly cohort was not powered enough to show a significant difference in terms of access site complications between TRA and TFA. 


\section{Future Directions}

- Next Steps

- A multicenter study may confirm our outcomes.

- This study was conducted at a single institution by operators with extensive experience in TRA, and thus our analysis would not reflect the profile of less experienced interventionalists in the elderly. 


\section{Acknowledgements}

- Special thanks to Ahmad Sweid for the opportunity and to all those who contributed to this project. 